\title{
Getting rhythm: how do babies do it?
}

\author{
Desaline Joseph, ${ }^{1,2}$ Nelson W Chong, ${ }^{2,3}$ Morag E Shanks, ${ }^{2,4}$ Ezio Rosato, ${ }^{2}$ \\ Nick A Taub, ${ }^{2}$ Stewart A Petersen, ${ }^{2}$ Michael E Symonds, ${ }^{1}$ William P Whitehouse, ${ }^{1}$ \\ Michael Wailoo ${ }^{2}$
}

- Additional material is published online only. To view please visit the journal online (http://dx.doi.org/10.1136/ archdischild-2014-306104).

${ }^{1}$ Division of Child Health, Obstetrics and Gynaecology, School of Medicine, University of Nottingham, Nottingham, UK

${ }^{2}$ College of Medicine, Biological Sciences and Psychology, University of Leicester, Leicester, UK ${ }^{3}$ Health and Human Sciences, University of Westminster, London, UK

${ }^{4}$ Nuffield lab of

Ophthalmology, University of Oxford, Oxford, UK

\section{Correspondence to}

Dr Desaline Joseph, Division of Child Health, Obstetrics and Gynaecology, School of Medicine, University of Nottingham, University Hospital, Derby Road, Nottingham NG7 2UH, UK; Desaline.Joseph@nuh.nhs.uk

Received 10 April 2014 Revised 27 August 2014 Accepted 29 August 2014 Published Online First 22 September 2014

\section{ABSTRACT}

Objectives To investigate the emergence of biological rhythms in the first months of life in human infants, by measuring age-related changes in core body temperature during night-time sleep, hormones (cortisol and 6-sulfatoxymelatonin) and the expression of a clock-controlled gene $\mathrm{H} 3 \mathrm{f3} \mathrm{b}$ in oral epithelial cells.

Design Observational longitudinal study.

Setting We measured overnight core body temperature, actigraphy, day-night urinary cortisol and 6-

sulfatoxymelatonin, as well as circadian gene expression, in infants at home from March 2007 to July 2008 in Leicester.

Participants We recruited 35 healthy Caucasian infants who were born at term. They were monitored from 6 to 18 weeks of age.

Results At 8 weeks of age the day-night rhythm of cortisol secretion was the first to appear followed by 6-sulfatoxymelatonin 1 week later; at the same time that night-time sleep was established. At 10 weeks, the maximum fall in deep body temperature occurred with the onset of night-time sleep, followed at 11 weeks by the rhythmical expression of the $H 3 f 3 b$ gene.

Conclusions In human infants, there is a clear sequential pattern for the emergence of diurnal biological rhythms between 6 and 18 weeks of postnatal age, led by the secretion of cortisol and linked with the establishment of consolidated night-time sleep. It is likely that this represents part of a maturation and adaption process as infants gain equilibrium with their external environment after birth.

\section{INTRODUCTION}

In utero, biological rhythms in the growing fetus are largely under maternal control. ${ }^{1}$ This maternal 'physiological protection' is relinquished at birth as the newborn begins to establish its own physiological and physical independence. Along with the obvious cardiorespiratory changes at birth, equally critical physiological adaptation takes place. This adaptation continues for the next 4-6 months ${ }^{2} 3$ as the infant consolidates sleep. Wailoo et $a l^{4}$ have documented the age-related changes in deep body temperature in infants during the early postnatal months and have identified some of the factors which may influence this development. ${ }^{5} 6$

In an extension of previous work, ${ }^{4}$ the main objective of our study was to ascertain, for normal infants, the development of biological rhythms and circadian gene expression. In this study, longitudinal measurements were made in the home on infants mainly during night-time sleep, while checking the expression of the circadian histone gene $H 3 f 3 b$ (see below) in buccal swabs, measuring

\section{What is already known on this topic?}

All organisms have biological rhythms.

- In mammals, these rhythms mature in very early postnatal life.

- Most data are in animals, not humans.

\section{What this study adds?}

- The human infant develops distinct biological rhythms in sequence.

- Cortisol appears to initiate and control this process.

- Infant biological rhythms are closely linked to sleep.

cortisol and 6-sulfatoxymelatonin (MT6s; a major melatonin metabolite) secretion in urine and monitoring changes in core body temperature at night.

Ultimately, we will establish the baseline of normal circadian rhythm development and be able to elucidate the phased integral physiological adaptation and maturation that is known to occur. In addition, we will identify biological clock mechanisms which are laid down antenatally and assembled simultaneously during that period of postnatal development.

\section{METHODS}

\section{Selection of participants}

We approached parents of singleton, full-term normal birthweight infants, on the postnatal ward at Leicester Royal Infirmary (UK), for an expression of interest, and recruited from March 2007 to July 2008.

We then visited parents once between weeks 4 and 6 , to explain the study and obtain written informed consent. Monitoring visits took place at home from 6 weeks to a maximum of 18 weeks on a fortnightly basis. Approval was given by the Local Research Ethics Committee.

\section{Body temperature measurements}

Three temperature probes were sited: a soft rectal probe inserted into the baby's rectum $5 \mathrm{~cm}$ from anal margin, a skin probe on the right shin and third, a probe to record the room temperature placed $30 \mathrm{~cm}$ from the cot. All probes were attached to a portable battery operated data logger (Squirrel 1201, 1202 models from Grant instruments Cambridge, UK) and were set to record
Chong NW, Shanks ME, et al. Arch Dis Child Fetal Neonatal Ed 2015;100 F50-F54. 
minute by minute throughout the night, beginning approximately $1 \mathrm{~h}$ before sleep and ending with final morning waking.

After the first recording, monitoring continued at fortnightly intervals until a mature temperature pattern during night-time sleep could be demonstrated, that is, a fall of deep body temperature below $36.5^{\circ} \mathrm{C}$ within $4 \mathrm{~h}$ of sleep onset. At the same time we measured sleep activity, collected urine samples and buccal smears as outlined below.

\section{Sleep activity}

No adjustments were made to the routine care or infant sleep environment. We fitted a mini Actiwatch (Cambridge Neurotechnology Limited, Cambridge, UK) around the ankle of each infant, which measures movement to obtain an approximation of rest and activity overnight as a proxy for sleep and wakefulness. Sleep onset was defined as the first period after recorded bedtime with at least 10 min of consecutive recorded immobile data (as per sleep-wake scoring algorithm). Mothers also kept a sleep diary.

\section{Urine collection}

Parents collected urine samples from their infant at midday and midnight for cortisol and MT6s estimation ${ }^{7}$ by fitting a Hollister U bag or pad (Uricol, Newcastle, UK) within $30 \mathrm{~min}$ of desired collection time. Samples were collected on two consecutive days, on a weekly basis. The MT6s urinary metabolite has a strong correlation with urinary/serum melatonin. ${ }^{8}$ Samples were frozen within $4 \mathrm{~h}$ and analysed by radioactive immunoassay (RIA; Stockgrand, University of Surrey, UK). We applied a standard correction for renal excretion. ${ }^{9}$

\section{Collection of buccal swabs for circadian gene analysis}

Each week parents took infant buccal swabs every $6 \mathrm{~h}$ over a 2-day period, using foam tipped Catch-all swabs (Epicentre, Madison, Wisconsin, USA). Swabs were preserved in RNA Later

Table 1 Description of participating infants and families

\begin{tabular}{|c|c|c|}
\hline & Count $(\%)$ & $95 \% \mathrm{Cl}^{*}$ \\
\hline \multicolumn{3}{|l|}{ Gender } \\
\hline Male & $15(43 \%)$ & (26 to 60$)$ \\
\hline Female & $20(57 \%)$ & \\
\hline Birth weight, $g$, mean (SD) & $3515(644)$ & \\
\hline Gestation weeks, mean (SD) & $39.6(1.35)$ & \\
\hline \multicolumn{3}{|l|}{ Feeding } \\
\hline Breast fed or partial breast fed & $29(73 \%)$ & (66 to 93 ) \\
\hline Bottle fed only & $6(17 \%)$ & \\
\hline \multicolumn{3}{|l|}{ Social class $\dagger$} \\
\hline Managerial/professional & $16(46 \%)$ & (29 to 63 ) \\
\hline Administration/sales/service & $5(14 \%)$ & (5 to 30$)$ \\
\hline Technical/skilled & $13(37 \%)$ & (21 to 55$)$ \\
\hline Unskilled & $1(3 \%)$ & (0.07 to 14$)$ \\
\hline \multicolumn{3}{|l|}{ Smoking status } \\
\hline Non-smoking & $19(54 \%)$ & \\
\hline Smoking & $16(46 \%)$ & (29 to 63 ) \\
\hline Birth order, mean (SD) & $1.7(0.94)$ & \\
\hline Weight at 10 weeks, $g$, mean (SD) $\ddagger$ & 5577 (973) & \\
\hline Maternal age, years, mean (SD) & $31.2(6.59)$ & (range 18-43) \\
\hline Paternal age, years, mean (SD) & $34.0(8.34)$ & (range 21-53) \\
\hline
\end{tabular}

(Ribose Nucleic Acid Later; Ambion, USA) and frozen at $-20^{\circ}$ C. The samples were then transported in dry ice and stored at $-80^{\circ} \mathrm{C}$ until analysis.

\section{Laboratory analysis}

Total RNA was extracted using the Qiagen RNAeasy mini kit. Yields varied from $20 \mathrm{pg} / \mu \mathrm{L}$ to $1 \mathrm{ng} / \mu \mathrm{L}$. We performed cDNA synthesis using the Transcriptor First Strand cDNA Synthesis kit (Roche Applied Science). Gene expression was measured by reverse transcription real-time quantitative PCR using the Opticon 1 (MJResearch) thermocycler. Swabs from infants rendered a very low yield of RNA, hence it was necessary to measure as an indicator of clock function, the rhythmical transcript of the gene Histone 3 family $3 b(\mathrm{H} 3 f 3 b) .{ }^{10}$ This produces a protein that makes up chromatin in the nucleus of eukaryotic cells and is expressed in a circadian fashion. ${ }^{11}$ The housekeeping gene glyceraldehyde 3-phosphate dehydrogenase $(G a p d h)$ was used as an internal control of amplification (further detail is provided in the online data supplement).

\section{Data analysis: definition of rhythm development}

We compiled the temperature data in 30-min intervals. A mature temperature rhythm was achieved at the age when maximum drop in core body temperature within the first $4 \mathrm{~h}$ of sleep onset occurred, as has been described previously. ${ }^{4}$ The actigraphy data were analysed using commercial software (Cambridge Neurotechnology, UK). We recorded the week of maximum sleep efficiency (percentage of time in bed that infant was asleep during night only). A diurnal rhythm for cortisol was achieved when more than $50 \%$ of total hormone was secreted during the day than at night, whereas the opposite was used for MT6s (ie, more secreted in the night than in day). ${ }^{12}$ The week circadian gene expression reached the maximum value or amplitude was selected as week of maturation of rhythm.

All main data outcomes had a normal distribution apart from MT6s and cortisol concentrations. These were logarithm transformed. We compared all data using mean values, SD and parametric tests. For circadian gene expression, a sine wave curve was fitted using the mean threshold $(\mathrm{Ct})$ value to assess the amplitude and phase of diurnal variation in peripheral gene expression. Analysis was undertaken using SPSS (V.16) and STATA (V.12) packages. The level for statistically significant results was set to $5 \%$.

\section{RESULTS}

We recruited 35 (15 male and 20 female) Caucasian infants, of which 18 (51\%) were exclusively breast fed, 7 (20\%) were breast fed up to 6 weeks of age and then formula fed, 4 (11\%) were fed a mixture of breast and formula feed and $6(17 \%)$ were exclusively formula fed. The mean \pm SD gestational age was $39.5 \pm 1.4$ weeks and average birth weight was $3515 \pm 644 \mathrm{~g}$ (see table 1).

\section{Core body temperature measurements}

One hundred and thirty-six temperature recordings were analysed, from 35 infants between 6 and 18 weeks, with each infant having a mean of 4.2 measurements (range 1-6). Eleven recordings were inadequate due to probe dislodgement or equipment failure.

The infants demonstrated an age-related, longitudinal change in core body temperature during night-time sleep. The mean core temperature (SD) just prior to sleep onset was $37.2^{\circ} \mathrm{C}\left( \pm 0.27^{\circ} \mathrm{C}\right)$ for all ages. The core temperature fell within $4 \mathrm{~h}$ of sleep onset (denoted as time 00:00 h) and the depth of this fall increased with age (figure 1). The core temperature remained low throughout the night, with a gradual rise in temperature as the infant approached 


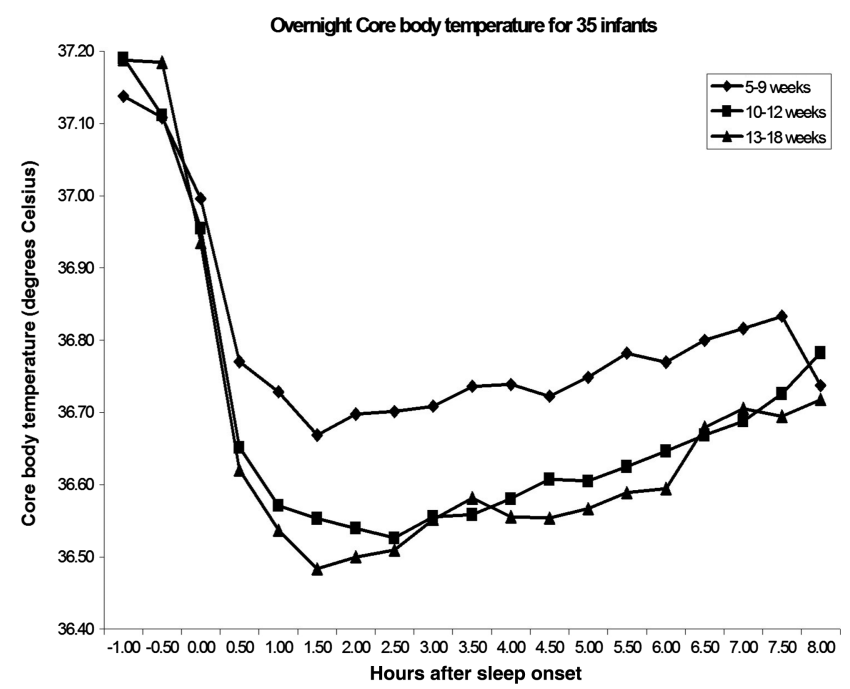

Figure 1 Mean core body temperature values for healthy term infants at 30-min intervals from $1 \mathrm{~h}$ prior to sleep onset to $8 \mathrm{~h}$ after sleep onset. Each infant was monitored at fortnightly intervals for one night only. The graph shows mean values grouped into intervals of 5-9 weeks, 10-12 weeks and 13-18 weeks with repeated measures. Error bars are excluded for clarity.

waking. The lowest value mean $(\mathrm{SD})$ was $36.4^{\circ} \mathrm{C}( \pm 0.43)$ at 10.8 weeks. There was no further fall with increasing age.

\section{Cortisol and MT6s secretion}

Four hundred and forty-six urine samples were analysed for cortisol estimation (22 insufficient samples) and 464 samples (four insufficient samples) for MT6s from 34 infants. Samples were collected very close to target times, on average at 23:47 h. for midnight and 11:50 h for midday collection.

Day-time cortisol secretion (SD) accounted for $60( \pm 21) \%$ of total cortisol secretion. There was no overall increase or decrease in cortisol secretion with age, either in the day or in the night.

Night-time secretion of MT6s (SD) was 51\% ( \pm 21$)$ of total, across all ages, which increased with age, week by week by $21 \%$ ( $p<0.001 ; 95 \%$ CI $13 \%$ to $29 \%)$. There was no overall change in day-time secretion.

We calculated mean cortisol and MT6s levels at fortnightly intervals and grouped these in weeks prior to and after onset of mature temperature. The difference between night and day values did not achieve statistical significance (figures $2 \mathrm{~A}, \mathrm{~B}$ ).

\section{Infant sleep}

We analysed 135 actigraphy readings from 35 infants with three readings lost due to equipment failure. Actigraphy (actual sleep time 20:42) confirmed parental reported mean bed time of 20:40 $(p=0.903)$. The mean (SD) total sleep duration for all infants was $7 \mathrm{~h}( \pm 1.8)$ per night, ranging from 3.5 to $10.5 \mathrm{~h}$ per night. The mean time (SD) taken to fall asleep once put to bed, that is, the sleep latency, was $15( \pm 11) \mathrm{min}$. The proportion of time (SD) infants were asleep, while in bed, that is, the sleep efficiency, was $75.3( \pm 10.9) \%$.

\section{Circadian gene expression}

A total of 22 infants had 599 buccal swab samples analysed from a total of 999 samples. One family had no refrigeration, another declined swab collection. Other samples were discarded due to illegible labelling. The remaining 10 infants did not have sufficient data (less than four consecutive six hourly samples/ week). Infants with no or insufficient samples were more likely
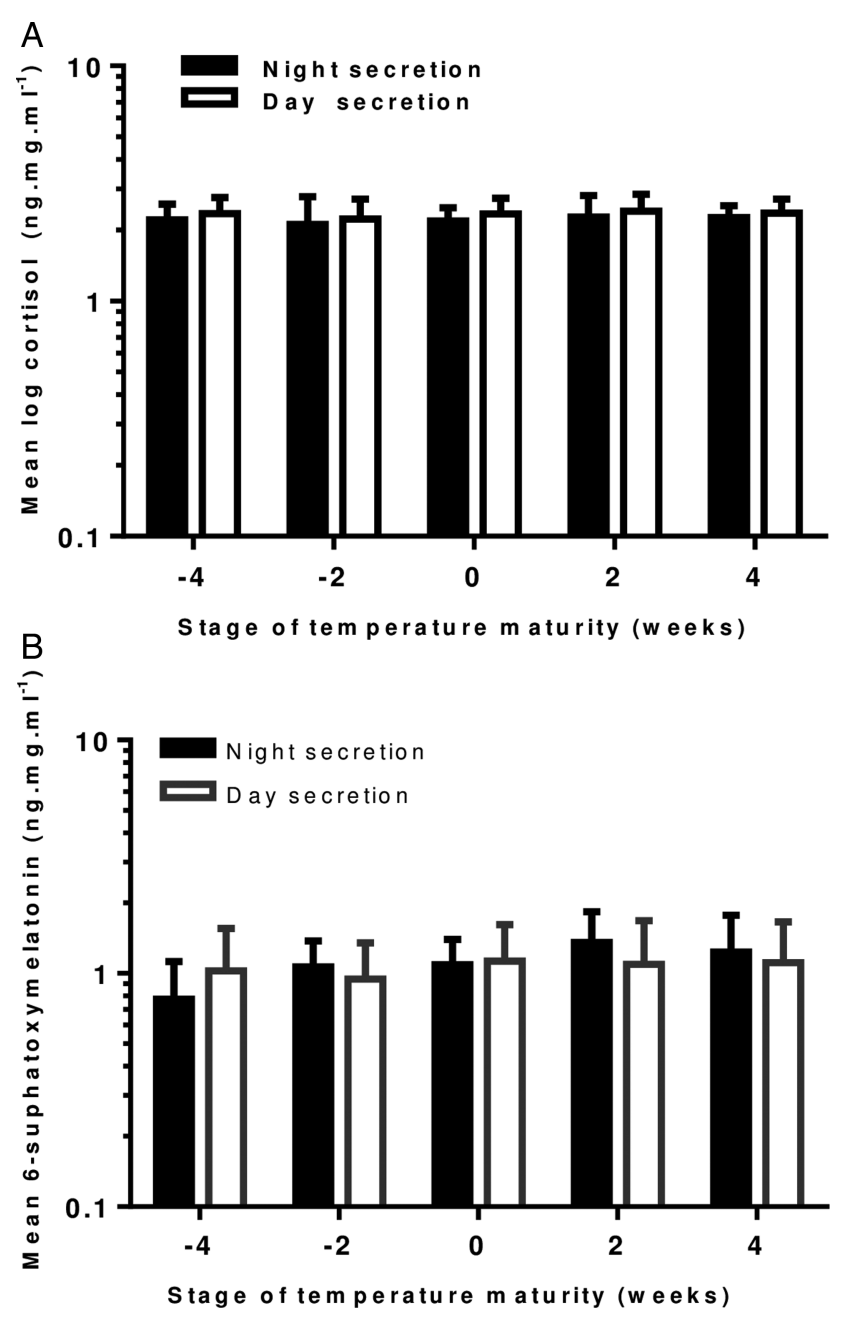

Figure 2 (A) Changes in day and night urinary cortisol concentration 4 weeks prior and 4 weeks after the development of a mature temperature pattern in healthy term infants. ( $n=14$ at -4 weeks, $n=21$ at -2 weeks, $n=17$ at 0 weeks, $n=18$ at 2 weeks and $n=7$ at 4 weeks). Error bars=1 SEM. (B) Graph showing changes in day and night urinary concentration of 6-sulfoxymelatonin four weeks prior and 4 weeks after the development of a mature temperature pattern in healthy term infants. ( $n=16$ at -4 weeks, $n=23$ at -2 weeks, $n=25$ at 0 weeks, $n=20$ at 2 weeks and $n=7$ at 4 weeks). Error bars $=1$ SEM.

to be from low social classes $\left(x^{2}=3.998 ; d f=1 ; p=0.046\right)$. No difference was observed for gender $(p=0.762)$, smoking status $(p=0.458)$, birth weight $(p=0.487)$, gestation $(p=0.695)$ and maternal age $(\mathrm{p}=0.794)$.

Linear modelling analysis showed a highly significant diurnal rhythm (sinusoidal pattern with intra/interinfant variation in amplitude and phase) with a 24 -hour period $(\mathrm{p}<0.001)$ and an overall estimated amplitude of 0.0126 (on same scale as $\mathrm{H} 3 \mathrm{f} 3 \mathrm{~b} /$ Glyceraldehyde-3-phosphate levels). The variation in the mean level of expression between the infants was also highly significant $(\mathrm{p}<0.001)$. The overall estimated time of day of maximum expression was 21:39 h. A representative circadian gene plot for one infant is shown in figure 3 . As the infant got older the closeness of fit of pattern to sinusoidal curve emerged, although this pattern was not universally maintained.

Timing of biological rhythms in relation to sleep

The maturation of the biological rhythms occurred in the following sequence. Maturation of the cortisol rhythm $(n=35$ 

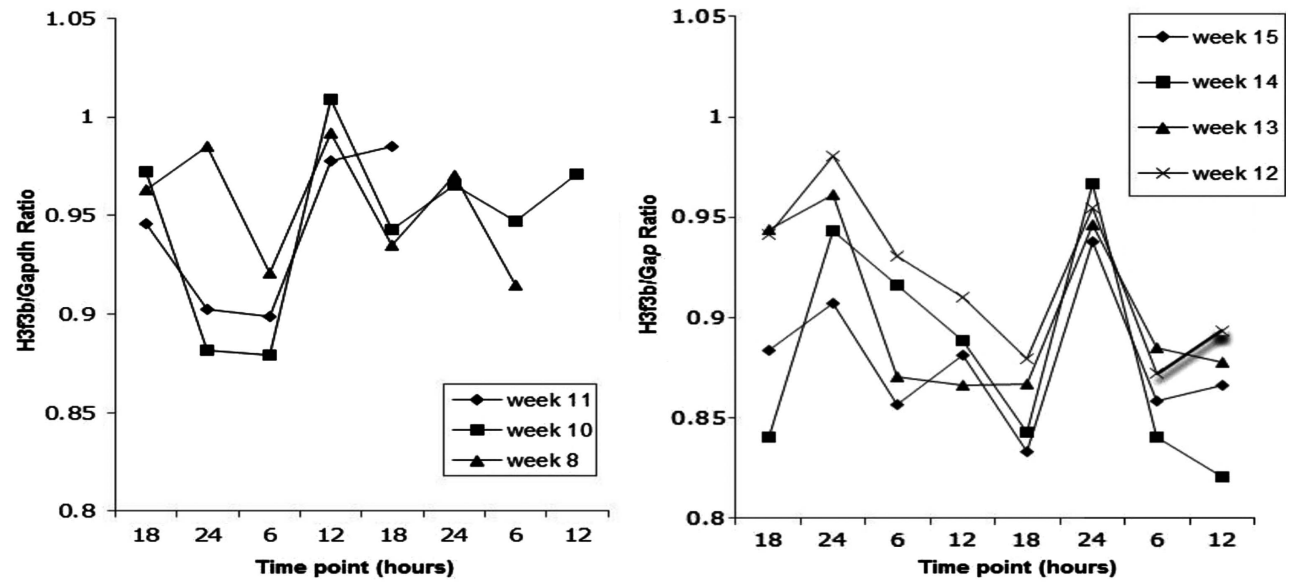

Figure 3 The quantitative analysis of the expression of a clock-controlled gene $\mathrm{H} 3 \mathrm{f3b}$ in oral epithelial cells from infant with identity number 16003 , shown as a ratio of $\mathrm{H} 3 \mathrm{f} 3 \mathrm{~b} / \mathrm{Gapdh}$. RNA was extracted and converted to CDNA by real-time PCR. Each sample was amplified in triplicate and the $\mathrm{H} 3 \mathrm{f} 3 \mathrm{~b}$ was then normalised to Gapdh gene expression. Mean $\mathrm{Ct}$ values were calculated. Weekly measurements were made over two consecutive days at approximately 18:00 $\mathrm{h}$ and 06:00 h. Sinusoidal plots are not shown. There are no data for week 9 due to insufficient samples.

infants) occurred first at 8.2 weeks of age. The melatonin metabolite MT6s ( $n=34$ infants) and sleep efficiency ( $n=35$ infants) rhythms occurred next at 9.1 and 9.4 weeks of age $(p=0.6524)$. Temperature maturation ( $\mathrm{n}=34$ infants) occurred at 10.8 weeks $(\mathrm{p}=0.053)$ and last of all, maximum peripheral circadian gene expression ( $n=21$ infants) at 10.9 weeks $(0.932$; figure 4$)$.

\section{DISCUSSION}

The findings of this study show that human infants adapt and mature physiologically during a process: integrated and ordered in an age-related manner. There is an emergence of a series of discreet physiological functions with that of cortisol in the lead at 8 weeks of age, followed a week later by the rhythmical secretion of MT6s (melatonin), the chemical messenger of the 'clock'. Then follows the establishment of maximum sleep efficiency also at 9 weeks and finally a mature deep body temperature rhythm at nearly 11 weeks together with peripheral Histone gene expression, that is, $H 3 f 3 b$.

This sequential pattern of the age-dependent development of individual physiological functions has similarly been described in the rat, where a cortisol response was present first at postnatal

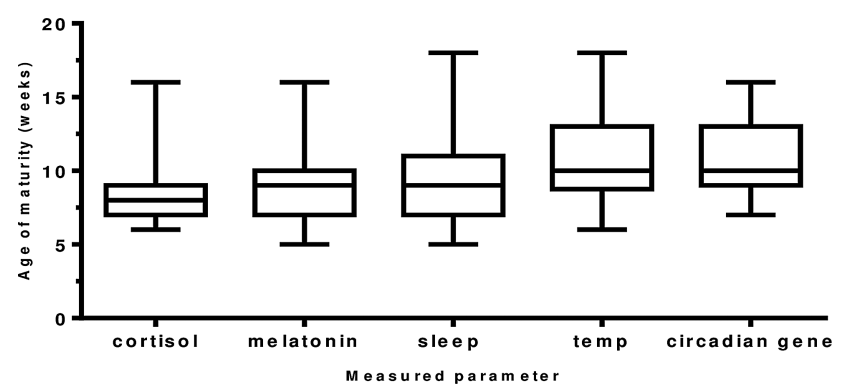

Figure 4 The age (in weeks) of maturation of the development of circadian rhythms in healthy term infants. A diurnal rhythm for cortisol and melatonin metabolite (6-sulfatoxymelatonin) was achieved when $>50 \%$ of total urinary secretion was achieved in day for cortisol and in the night for melatonin metabolite. Age of maturity of core body temperature was achieved when minimum temperature of $36.4^{\circ} \mathrm{C}$ occurred within first $4 \mathrm{~h}$ of sleep onset; for sleep, maturity was denoted as the week maximum sleep efficiency was obtained and for the peripheral circadian gene $\mathrm{H} 3 \mathrm{f} 3 \mathrm{~b}$ the week maximum amplitude occurred. Number of infants: cortisol $(n=35)$, melatonin metabolite $(n=34)$, sleep $(n=35)$, temperature $(n=35)$ and H3f3b gene expression $(n=22)$. day 14 , but a full circadian rhythm not established until later. ${ }^{13}$ Thermoregulatory control was seen within 19 days, ${ }^{14}$ sleep maturation with a decrease in rapid eye movement (REM) sleep observed from days 14 to $27^{15}$ and maximum melatonin retinal uptake at day $20 .^{16}$

This appears to give cortisol a pivotal role as an instructor of independent physiological function in the newborn, and an entrainer of an integrated biological clock which enables the human infant to adjust to its new environment as Dickmeis ${ }^{17}$ has shown in other animals. Of interest, exogenous glucocorticoids are known to synchronise circadian gene expression in diverse cell types and tissues in culture, ${ }^{18}{ }^{19}$ possibly via the glucocorticoid response elements located in the DNA regulatory regions of central clock genes. ${ }^{20}$ Cortisol production in utero and subsequent early maturation of hypothalamic pituitary adrenal axis suggest that there is a prenatal regulatory role ${ }^{21}$ that extends into life postnatally. ${ }^{2} 22$ The emergence of the rhythmical secretion of melatonin soon after that of cortisol suggests a temporal relationship and may be mediated by the steroid-dependent transition of the enzyme, which produces the melatonin precursor serotonin. ${ }^{23}$ The timing of the rhythms may vary with studies finding a melatonin morning peak after 3 months of age ${ }^{24}$ and a declining morning cortisol level from 6 weeks onwards. ${ }^{25}$ The evening peak of melatonin secretion shown in this study, however, coincides with the development of a consolidated day-night sleep-wake cycle.

It is not surprising that sleep efficiency improves with evening secretion of melatonin with its sleep promoting and phase shifting properties ${ }^{26}$ emphasising the importance of this relationship in the first months of life. ${ }^{27}$ However, as actigraphy has yet to be validated in infants ${ }^{28}$ and has a low specificity (39\%) for wakefulness after sleep onset, ${ }^{29}$ alternative methods of measurement of sleep should be considered in future studies to characterise sleep more accurately.

With maximum sleep efficiency, we saw a characteristic fall in core body temperature at sleep onset. The likelihood is that core body temperature fell as a direct result of sleep, as observed with other physiological functions such as heart rate and that sleep was not initiated by a fall in core temperature as suggested by Kräuchi et al. ${ }^{30}$ Whether more accurate measures such as the assessment of rapid eye movement ${ }^{31}$ by polysomnography would be a more sensitive marker of early sleep maturation ${ }^{32}$ is open to question. 
All rhythms are thought to be controlled by the body's master clock, the suprachiasmatic nucleus, the elements of which are laid down in utero. These are gradually assembled postnatally under neuronal and hormonal control (eg, cortisol and melatonin), leading to the expression of regulatory genes, whose role has not been previously described in human infants. The genetic basis for circadian rhythmicity has been mainly from animal work. $^{33}$ In spite of methodological and practical difficulties, such investigation can be undertaken on human infants. Tissues such as epithelial cells are accessible and provide genetic material from which the maturation of the clock can be monitored. ${ }^{10}$

The distinct sinusoidal pattern of gene expression in H3f3b transcripts in buccal mucosa occurred at 11 weeks, with a mean peak of 21:39 h. Although we could not accurately explain how the pattern of peripheral gene expression relates to key clock genes due to minimal RNA extraction and the wide intrainfant and interinfant variations with age; we may nonetheless speculate that gene expression in peripheral organs (which is tissue specific) may depend on prior rhythm establishment in physiology and behaviour.

Limitations included the time commitment from families and the sensitivity and specificity of methods used. Different methods would have allowed more precise elucidation of the rhythms, distinguishing shorter ultradian from $24 \mathrm{~h}$ rhythms. However, other work has had similar constraints on frequency of measures and methods. ${ }^{24} 253435$ The main strength of this study was that mothers acted as the primary research assistant, thereby enabling it to be conducted in the home, reflecting physiological maturity in a natural environment.

In conclusion, fetal rhythms continue to develop postnatally. In infants, delays in circadian rhythm development may be linked to infant mortality such as sudden infant death syndrome. ${ }^{36}$ Emerging paediatric research is highlighting the contribution of circadian rhythm disruption to morbidity and mortality ${ }^{37} 38$ and this is being incorporated into principles of clinical practice. ${ }^{39}$ Acknowledgements We thank Dr Benita Middleton for assistance with hormone
assays and Professor John Thompson for invaluable statistical advice and support.

Contributors DJ collected the data, carried out initial analyses, drafted and revised the manuscript and approved the final manuscript as submitted. NWC contributed to study design, supervised data analyses, reviewed and revised manuscript and approved final manuscript as submitted. MES conducted gene expression analyses, reviewed and revised the manuscript and approved the final manuscript as submitted. NAT supervised initial analyses and conducted secondary analyses, critically reviewed and revised manuscript and approved final manuscript as submitted. ER contributed to study design, supervised gene expression analyses, reviewed and revised manuscript and approved final manuscript as submitted. SAP, MES and WPW critically appraised, reviewed and revised manuscript and approved final manuscript as submitted. MW conceptualised and designed the study, supervised data collection and initial analyses, reviewed and revised manuscript and approved final manuscript as submitted.

Funding This study was supported by a grant from Babes in Arms and Leicester City West Primary Care Trust.

\section{Competing interests None.}

Patient consent Obtained.

Ethics approval Local Research Ethics and Committee (LREC) Ref 06/Q2405/27.

Provenance and peer review Not commissioned; externally peer reviewed.

\section{REFERENCES}

1 Mirmiran M, Lunshof S. Perinatal development of human circadian rhythms. Prog Brain Res 1996;111:217-26.

2 Santiago LB, Jorge SM, Moreira AC. Longitudinal evaluation of the development of salivary cortisol circadian rhythm in infancy. Clin Endocrinol 1996;44:157-61.

3 Kennaway DJ. Melatonin and development: physiology and pharmacology. Semin Perinatol 2000;24:258-66.

4 Lodemore M, Petersen SA, Wailoo MP. Development of night time temperature rhythms over the first six months of life. Arch Dis Child 1991;66:521-4.
5 Wailoo MP, Westaway JA, Joseph D, et al. Overnight deep body temperature and urinary cortisol excretion in infants from economically deprived areas. Child Care Health and Dev 2003;29:473-80.

6 Jackson JA, Wailoo M, Thompson J, et al. Early physiological development of infants with intrauterine growth retardation. Arch Dis in Childhood Fetal Neonatal Ed 2004;89:F46-50.

7 Arendt J, Bojkowski C, Franey C, et al. Immunoassay of 6-hydroxymelatonin sulfate in human plasma and urine: abolition of the urinary 24-hour rhythm with atenolol. J Clin Endoc Met 1985;60:1166-73.

8 Bojkowski CJ, Arendt J, Shih MC, et al. Melatonin secretion in humans assessed by measuring its metabolite, 6-sulfatoxymelatonin. Clin Chem 1987;33:1343-8.

9 Klante $G$, Brinschwitz $T$, Secci $K$, et al. Creatinine is an appropriate reference for urinary sulphatoxymelatonin of laboratory animals and humans. J Pineal Res 1997;23:191-7

10 Maxson R, Cohn R, Kedes L, et al. Expression and Organization of Histone Genes. Annu Rev Genet 1983;17:239-77.

11 Etchegaray J, Lee C, Wade PA, et al. Rhythmic histone acetylation underlies transcription in the mammalian circadian clock. Nature 2003;421:177-82.

12 Sivan $Y$, Laudon $M$, Tauman $R$, et al. Melatonin production in healthy infants: evidence for seasonal variations. Pediatr Res 2001;49:63-8.

13 Levine S. The Ontogeny of the Hypothalamic-Pituitary-Adrenal Axis. The Influence of Maternal Factors. Ann N Y Acad Sci 1994;746:275-88.

14 Spiers DE, Adair ER. Ontogeny of homeothermy in the immature rat: metabolic and thermal responses. J Appl Physiol 1986;60:1190-7.

15 Vogel GW, Feng P, Kinney GG. Ontogeny of REM sleep in rats: possible implications for endogenous depression. Physiol Behav 2000;68:453-61.

16 Bubenik G, Purtill R, Brown G, et al. Melatonin in the retina and the Harderian gland. Ontogeny, diurnal variations and melatonin treatment. Exp Eye Res 1978;27:323-33.

17 Dickmeis T. Glucocorticoids and the circadian clock. J Endocrinol 2009;200:3-22.

18 Gómez-Abellán P, Díez-Noguera A, Madrid JA, et al. Glucocorticoids affect $24 \mathrm{~h}$ clock genes expression in human adipose tissue explant cultures. PLoS ONE 2012;7:e50435.

19 Balsalobre A, Brown SA, Marcacci L, et al. Resetting of circadian time in peripheral tissues by glucocorticoid signaling. Science 2000;289:2344-7.

20 So AY, Bernal TU, Pillsbury ML, et al. Glucocorticoid regulation of the circadian clock modulates glucose homeostasis. Proc Natl Acad Sci 2009;106:17582-7.

21 Challis JR, Matthews SG, Gibb W, et al. Endocrine and paracrine regulation of birth at term and preterm. Endocr Rev 2000;21:514-50.

22 Onishi S, Miyazawa G, Nishimura Y, et al. Postnatal development of circadian rhythm in serum cortisol levels in children. Pediatrics 1983;72:399-404.

23 Maximino C. Serotonin and anxiety. Neuroanatomical, pharmacological and functional aspects. In: Maximino C, ed. Serotonin in the nervous system of vertebrates. New York: Springer, 2012:15-36.

24 Shinohara H, Kodama H. Relationship between circadian salivary melatonin levels and sleep-wake behavior in infants. Pediatri Int 2011;53:29-35.

25 Tollenaar MS, Jansen J, Beijers R, et al. Cortisol in the first year of life: Normative values and intra-individual variability. Early Hum Dev 2010;86:13-16.

26 Zhdanova IV, Lynch HJ, Wurtman RJ. Melatonin: a sleep-promoting hormone. Sleep 1997:20:899-907.

27 Kennaway D, Stamp G, Goble F. Development of melatonin production in infants and the impact of prematurity. J Clin Endocrinol Metab 1992;75:367-9.

28 Insana SP, Gozal D, Montgomery-Downs HE. Invalidity of one actigraphy brand for identifying sleep and wake among infants. Sleep Med 2010;11:191-6.

29 Hyde M, O'Driscoll DM, Binette S, et al. Validation of actigraphy for determining sleep and wake in children with sleep disordered breathing. J Sleep Res 2007;16:213-16.

30 Kräuchi K, Cajochen C, Werth E, et al. Functional link between distal vasodilation and sleep-onset latency? Am J Physiol Regul Integr Comp Physiol 2000;278:R741-8.

31 Graven SN, Browne JV. Sleep and brain development: the critical role of sleep in fetal and early neonatal brain development. Newborn Infant Nurs Rev 2008;8:173-9.

32 Coons S, Guilleminault C. Development of sleep-wake patterns and non-rapid eye movement sleep stages during the first six months of life in normal infants. Pediatrics 1982;69:793-8.

33 Reppert SM, Weaver DR. Coordination of circadian timing in mammals. Nature 2002:418:935-41.

34 Navelet $\mathrm{Y}$, Benoit $\mathrm{O}$, Bouard $\mathrm{G}$. Nocturnal sleep organization during the first months of life. Electroencephalogr Clin Neurophysiol 1982;54:71-8.

35 de Weerth C, van Geert P. A longitudinal study of basal cortisol in infants: Intra-individual variability, circadian rhythm and developmental trends. Infant Behav Dev 2002;25:375-98.

36 Bajanowski T, Vege Å, Byard RW, et al. Sudden infant death syndrome (SIDS)-Standardised investigations and classification: Recommendations. Forensic Sci Int 2007;165:129-43.

37 Joosten K, De Kleijn E, Westerterp M, et al. Endocrine and metabolic responses in children with meningococcal sepsis: striking differences between survivors and nonsurvivors. J Clin Endocrinol Metab 2000;85:3746-53.

38 Marseglia L, Aversa S, Barberi I, et al. High endogenous melatonin levels in critically III children: a pilot study. J Pediatr 2013;162:357-60.

39 Rivkees SA, Mayes L, Jacobs $\mathrm{H}$, et al. Rest-activity patterns of premature infants are regulated by cycled lighting. Pediatrics 2004;113:833-9. 